\title{
Preliminary assessment of the numerical competencies of children from a public preschool and kindergarten in Cuenca
}

\author{
Gina Bojorque ${ }^{1}$, Joke Torbeyns ${ }^{2}$ \\ ${ }^{1}$ Facultad de Filosofía, Universidad de Cuenca, Cuenca, Ecuador. \\ ${ }^{2}$ Center for Instructional Psychology and Technology, Faculty of Psychology and Educational \\ Sciences, KU Leuven, Leuven, Belgium.
}

Autor para correspondencia: gina.bojorque@ucuenca.edu.ec

Fecha de recepción: 9 de febrero de 2015 - Fecha de aceptación: 24 de marzo de 2015

\begin{abstract}
There is abundant evidence that young children are capable of developing mathematical knowledge and that the arithmetic skills of young children are a predictor of their future academic achievement. There is also a common agreement that the quality of early mathematical instruction has an important influence on children's subsequent learning. In Ecuador studies on young children's early mathematical competencies and instruction are scare. Therefore a study was initiated to (1) assess the numerical competencies of preschoolers and kindergartners (first year of elementary education) attending a public school in Cuenca, with the objective to critically analyze their numerical thinking and reasoning, and (2) examine teachers' practices and believes regarding early mathematical instruction and children's mathematical competencies. An application of the Number Knowledge Test (Griffin, 2005) demonstrated that most of the participating children had not developed basic numerical competencies. In addition, teachers strongly believe that young children are incapable of carrying out mathematical thoughts. As a consequence, mathematical activities in which children and teachers are engaged are insufficiently developed. The scientific and practical implications of these results are discussed.
\end{abstract}

Keywords: Early numeracy, preschoolers, kindergartners, mathematical competencies.

\section{RESUMEN}

Existe abundante evidencia de que los niños pequeños son capaces de desarrollar un conocimiento matemático y que las destrezas aritméticas de estos niños son predictores de su desempeño académico futuro. También existe un acuerdo común de que la calidad de la educación matemática inicial tiene una importante influencia en el aprendizaje posterior de los niños. En Ecuador hay escasos estudios sobre las competencias matemáticas tempranas de los niños y sobre su enseñanza. Por ello, se inició un estudio para (1) evaluar las competencias numéricas de los niños de pre-escolar y kindergarten (primero de básica) que asisten a una escuela pública de Cuenca, con el objetivo de analizar críticamente su pensamiento y razonamiento numérico; y (2) examinar las prácticas y creencias de los profesores con relación a la enseñanza de la matemática y a las competencias matemáticas de los niños. La aplicación del Test de Conocimiento Numérico (Griffin, 2005) demostró que la mayoría de los niños participantes no habían desarrollado habilidades numéricas básicas. Adicionalmente, los profesores expresaron una fuerte creencia de que los niños pequeños no son capaces de tener un pensamiento matemático. Como consecuencia, las actividades matemáticas que realizan los niños y profesores son desarrolladas de manera insuficiente. Las implicaciones científicas y prácticas de estos resultados son discutidas.

Palabras clave: Matemática inicial, pre-escolar, jardín de infantes, competencias matemáticas. 


\section{BACKGROUND}

Mathematics is used in everyday-life by children all over the world. During the first years of life children count, measure, compare sizes, match pairs, recognize numbers and do a variety of things related to mathematics. Likewise, it has been widely accepted that young children's early mathematical competencies have an important influence on their subsequent learning (Aunio \& Niemivirta, 2010; De Smedt et al., 2009; Duncan et al., 2007; Geary, 2011; Jordan et al., 2009; Krajewsky \& Schneider, 2009), and that high quality mathematical instruction for 3-6 year old children is crucial for their future mathematics learning (Fuson, 2004). In the following, a brief review of the literature related to the mathematical knowledge of young children is presented, followed by the importance of improving those competencies during the early years of schooling as basis for later learning via appropriate teaching practices. Next, the influence of the socioeconomic status on young children's mathematical development is analyzed, to finally present some recommendations that might result in an improvement of the quality of early mathematical education.

\subsection{Young children's mathematical competencies}

For a long time it was thought that children in preschool years did not possess mathematical knowledge (Starkey et al., 2004) because it was generally accepted that their capacity for numerical understanding was restricted by their cognitive characteristics (Piaget, 1969). For this reason, it was believed that the development of mathematical knowledge only began in elementary school with formal instruction in mathematics (Bereiter \& Engelman, 1966). These views contributed to the rational to restrict mathematical instruction in early years (Baroody et al., 2006). However, recently there has been a growing realization of children's mathematical skills before elementary school. It has been demonstrated that young children's knowledge of mathematics is extensive, often sophisticated (Clements \& Sarama, 2007; Sarama \& Clements, 2009; Warfield, 2001). During the early years, children experience a diversity of situations that allow them to learn a variety of things about number; for instance, counting the members of the family, or dividing a cake so everyone gets the same amount. By the time children enter kindergarten they can correctly count sets of objects greater than 10, compare collections of objects and tell which collection has more/less objects, and are able to solve simple arithmetic problems by means of counting (Sarama \& Clements, 2009; Kilpatrick et al., 2001). Moreover, they develop the ability to apprehend the quality of a collection by means of subitizing. Subitizing is defined as an accurate and fast recognition of a small number of items in a collection without counting (e.g. quickly and accurately recognizing $* * *$ as a collection of three items) (Baroody, 2004; Clements \& Sarama, 2007; Sarama \& Clements, 2009).

The initial understanding of numbers and arithmetic constitutes children's informal knowledge. Starkey et al. (2004) identified that some aspects of this informal mathematical knowledge (e.g. enumeration, ordering, number comparison, arithmetic problem solving) develop considerably during preschool years and constitute the basis for the acquisition of formal mathematics in school. The quality and quantity of mathematical knowledge acquired by children in their early years provides the foundation on which children's learning of more complex number concepts is built (Kilpatrick et al., 2001). Furthermore, the amount of mathematical knowledge with which children enter school is more and more recognized as a strong predictor of future success (Duncan et al., 2007; Jordan et al., 2010).

\subsection{Early mathematical instruction}

Baroody et al. (2006) argue that it is important for teachers to become aware of the rich informal mathematical knowledge that each child brings to school as formal instruction should build on this informal knowledge. The authors also state that if mathematics is not presented to children in a way that makes sense to them, i.e. built on their informal knowledge, this might lead to learning difficulties at later age.

Within the domain of mathematics education, number and operations has been identified as the most important area in early childhood (Baroody, 2004; Clements, 2004; Fuson, 2004; Griffin \& Case, 1997). Researchers agree that mathematical instruction in this area should concentrate on helping 
children to develop the big ideas of learning. With big ideas is understood the teaching of concepts and skills that connect numerous topics and that are consistent with children's levels of thinking (Clements \& Sarama, 2009). Six key big ideas are considered essential to be taught in preschool years (Baroody, 2001; Baroody et al., 2004; Baroody et al., 2006), namely: (1) counting can be used to find out how many in a collection or for making a collection of a particular size; (2) numbers can be used to compare or order collections of objects; (3) collections can be made larger by adding items to it and smaller by taking some items away from it; (4) a quantity (a whole) can consist of parts and can be broken apart (decomposed), and the parts can be combined (composed) to form the whole; (5) items can be grouped to make a larger unit and written in a multi-digit number, the value of a digit depends on its position; and (6) a quantity (whole) can be partitioned (decomposed) into equal size pieces (parts).

Besides these big ideas, it is also fundamental that teachers are knowledgeable of both the natural developmental progression of children in learning mathematics, and of effective teaching strategies that help children to achieve higher levels of thinking (Baroody et al., 2006; Clements \& Sarama, 2009). In relation to the first aspect it is crucial for teachers to consider the timing of teaching. In this sense, during the process of developing mathematic curricula for the early years, it is important to take into account the developmental readiness of students (Baroody et al., 2006). That is to say, that the content presented to children should not be too advanced for their cognitive and behavioral characteristics (Sophian, 2004) and should follow the natural developmental progression. In this context, Baroody et al. (2004) caution that teachers should carefully select the topics, activities and problems to be taught and the sequence in which they are presented. This will facilitate children to construct the knowledge network that they are expected to achieve according to their age level and will constitute the basis upon which more sophisticated knowledge is built (Griffin, 2005).

Regarding the second aspect, i.e. effective teaching strategies, it is important that teachers use the most adequate instructional methods for fostering effective learning. According to Baroody et al. (2006) both the Guided Discovery Learning and the Flexible Guided Discovery are the most promising teaching methods. In the Guided Discovery Learning approach the teacher takes the initiative of the activities, offering challenging tasks and/or questions that are planned beforehand and that stimulate the development of children's competencies. Once these tasks and questions are offered, the teacher guides the children in their development. In the Flexible Guided Discovery approach it is the child who initiates the activities. The role of the teacher is to take advantage of the opportunities offered by the children to raise challenging questions or tasks that may stimulate their development. A combination of both approaches seems to yield the most effective results (Baroody et al., 2006).

Despite all these findings and the efforts to understand and improve the mathematical development of young children, some researches claim that the mathematics children receive at some preschool and kindergarten settings is inadequate (Copley, 2004; Starkey et al., 2004; Greenes et al., 2004). An aspect influencing this inadequacy is the early childhood teachers' knowledge and beliefs. Namely, it has been reported that many early year educators do not know how to support children's development of numerical abilities; they are often uncomfortable with mathematics and believe that mathematic experiences are not necessary in preschool years (Copley, 2004). The latter suggests that many teachers and caregivers not exactly know how to teach mathematics to young children. Notwithstanding, it has been proven imperative to provide greater mathematics enrichment to all preschool children, in particular to children from the lower socioeconomic class of the society who have fewer educational opportunities (Raudenbush, 2009).

\subsection{Socioeconomic status as a key factor of mathematical success}

Notwithstanding the recognition that children's mathematical competencies should be stimulated during the early years, unfortunately not all children have the same opportunity to develop a robust mathematical understanding. As stated by Barnett \& Belfield (2006), the low socioeconomic status does have a detrimental influence on children's development. Proof of it was given by Starkey et al. (2004) who reported that middle-class children outperform children from low-income families on at least some number and arithmetic tasks, and that socioeconomic disadvantaged children typically lack basic number knowledge that their peers form middle-income families possess. According to Jordan et 
al. (2006) those children enter school with specific gaps in their mathematical proficiency. Furthermore, it is generally agreed that children with low skills at school entry tend to continue being low achievers throughout their formal education (Evans \& Rosenbaum, 2008); many develop math anxiety, do not want to engage in more advanced mathematical courses, or simply disengage from mathematics (Wright, 1994). Baroody et al. (2006) state that the initial disadvantage in young children's mathematical competence is additionally compounded by the inadequate formal instruction they receive. They pointed out that the inadequacy of preschool and kindergarten learning environments is especially problematic for economically disadvantaged children because the schools that serve children from deprived socioeconomic backgrounds are generally less qualified than those serving more advantaged children. Additionally, they argued that schools serving low-income children have less competent teachers and fewer technological resources, an element to be considered when evaluating young children's mathematical competencies.

\section{THE PRESENT STUDY}

As stated, the acquisition of good preparatory mathematical skills at young ages is fundamental in developing mathematical fluency at later ages. Information on preparatory mathematical skills in Ecuador does not exist, but studies in youth demonstrate that Ecuadorian students perform low in the area of mathematics in national (e.g. Ministerio de Educación, 2012) and international (e.g. UNESCO, 2008) tests. Therefore, the first goal of this study was to assess the numerical competencies of preschoolers and kindergartners (first year of elementary education) attending a public school in Cuenca, aiming at critically analyzing their numerical thinking and reasoning. Internationally, several tests to measure children's early mathematical competencies are available and have been widely applied, such as the Number Knowledge Test (Griffin, 2005), the Test of Early Mathematics Assessment (TEMA-III) (Ginsburg \& Baroody, 2003), the Tools for Early Assessment in Math (TEAM) (Clements et al., 2011), and the Early Numeracy Test (ENT) (Van de Rijt et al., 1999). For the purpose of this study, the Number Knowledge Test (Griffin, 2005), was used for the following reasons: (1) the test allows to determine children's level of numerical understanding and thinking; (2) the test is based on research on children's cognitive development; and (3) the test is simple to administer (Griffin, 2005). Parallel to the assessment of the children's mathematical competencies, the study also aimed at examining the teachers' practices and believes related to mathematics instruction of young children.

\section{METHODOLOGY}

\subsection{Participants}

The Number Knowledge Test was applied to 49 4- to 5-year-olds involving seventeen preschoolers from one class: 10 male and 7 female and 32 kindergartners from two classes: 19 male and 13 female, belonging to a public school in Cuenca. $73 \%$ of the Ecuadorian children attend public schools (Ministerio de Educación, 2013). Most of those children belong to the lower fraction of the middleincome and the lower-income families; thus, most likely the majority of the participating children of this study belong to a socioeconomic disadvantaged family. The study took place during the middle of the school year. The mean age of the preschoolers at the moment of the application of the test was 4 years 6 months ( $\mathrm{SD}=3.8$ months), whereas the mean age of the kindergartners was 5 years 7 months ( $\mathrm{SD}=3.9$ months). In addition to the forty nine children, the female teachers of the above mentioned three classes were interviewed. 


\subsection{Materials}

\section{Number knowledge test}

In order to measure the children's numerical competencies, the Number Knowledge Test (Griffin, 2005) was administered. This test provides a portrait of the number knowledge children typically have available at several specific age levels between 4 and 8 years. The test is divided into 3 levels, namely, Level 0 (4-year-olds) consisting of 5 items, 2 of them involving two parts: A and B; Level 1 (6-yearolds) comprising 9 items, 4 of them involving two parts: A and B; and Level 2 (8-year-olds) also comprising 9 items with 3 two-part items. The age associated with each level of the test represents the midpoint in the 2-year age period during which number knowledge is typically developed. Hence, Level 0 for 4-year-olds captures children's thinking between the ages of 3 and 5 years, and Level 1 for 6-year-olds captures children's thinking between the ages of 5 and 7 years. The starting point of the test is a preliminary question from which the rest of the questions are set. Due to the age of children in this study, only levels 0 and 1 were administered (see Appendix 1 for a description of the Test).

The test requires an individual administration, and the questions are presented to the children orally demanding an oral response from them. Test administrators make use of a follow-up question, i.e. "How did you figure that out?" for questions 1, 3, and 7 at Level 1. These questions provide additional insights into children's reasoning and strategy. At the 4-year-old level (i.e. Level 0), items are presented with physical objects, whereas items at the 6-year-old level (i.e. Level 1) are presented without physical objects. The test is scored dichotomously on correctness (one point is assigned for each item passed). For the two-part items, both part A and part B must be passed to get a point.

The Number Knowledge Test was translated into Spanish by the author of the article. Before administering the test to the participants, a pre-test of the questionnaire was conducted with 105 -yearolds from another public school in order to observe how children perceived the test and the difficulties they may face. After evaluation of the children's questionnaires, the language of the test was revised to assure that every child clearly understand the instructions.

\section{Teachers' questionnaire}

To examine the teachers' practices and believes, a teachers' questionnaire was developed by the authors, based on her experience with the Ecuadorian school system as a kindergarten teacher. The questionnaire consisted of 9 questions (see Appendix 2) that involves aspects related to teachers' background, their beliefs about children's informal mathematical understanding and the importance of early mathematics education. The questionnaire also included questions regarding mathematics instruction in terms of what contents and how those contents are taught to children as well as the amount of time they spend in teaching mathematics.

\subsection{Procedure}

The children were individually tested in a separate room at their own school. Preschoolers were evaluated first, followed by kindergarteners. The administration of the test absorbed 15 to 20 minutes. After completion of the test, three teachers were individually interviewed. The applied methodology can be described as a cross-sectional descriptive study, consisting of a semi quantitative-qualitative approach, applied on a small sample of children and teachers. The results therefore only provide a snapshot of a population sample at a certain time, permitting testing the validity and viability of the applied methodology, for future larger scale cross-sectional surveys.

\section{RESULTS}

\subsection{Preschoolers}

The preliminary item of the test required children to count from 1 to 10. It was found that seven out of the seventeen children were able to say the counting words correctly. An in-depth analysis of those who were unsuccessful in counting showed that all of them could say the first three numbers in the 
right order, but after number 3 , they muddled up the numbers. The most common errors made were: (1) miss some numbers out (e.g. 1, 2, 3, 4, 7, and 10); (2) put some numbers in the wrong order (e.g. 1, $2,3,6,5,7 \ldots$ ); and (3) say the numbers unsystematically (e.g. 1, 2, 3, 40, 18, 12..).

Regarding the Level 0 responses (see Table 1), it was found that six out of the seventeen children knew how to count correctly a set of three chips that were placed in front of them (Item 1), and tell how many there were. Another four children were able to count the three chips correctly, "one, two, three", but were not able to give the last number said (i.e. three) as the answer. When asked how many chips there were, they started to recount, not realizing that the last number word tells them how many there were. The seven remaining children were unable to count. One of them counted by saying "one", "one", and "one", whereas the common mistake made by the others was to say more words than chips touched.

Table 1. Number of children that correctly answered the test items.

\begin{tabular}{lcc}
\hline Items & Preschoolers $(\mathrm{N}=17)$ & Kindergartners $(\mathrm{N}=32)$ \\
\hline Preliminary item & 7 & 21 \\
Level 0 & & \\
Item 1 & 6 & 27 \\
Item 2 & 11 & 30 \\
Item 3 & 9 & 30 \\
Item 4 & 6 & 20 \\
Item 5 & 1 & 13 \\
Level 1 & & \\
Item 1 & 0 & 0 \\
Item 2 & 1 & 8 \\
Item 3 & 1 & 5 \\
Item 4 & 1 & 2 \\
Item 5 & 0 & 2 \\
Item 6 & 0 & 0 \\
Item 7 & 0 & 0 \\
Item 8 & 0 & 0 \\
Item 9 & 0 & 0 \\
\hline
\end{tabular}

The six children who successfully answered Item 1 were also able to solve the more advanced counting problem posed in Item 4. But the other eleven children were unsuccessful in solving these problems. Common mistakes were: (1) counting all the chips without differentiating the color; (2) counting two times the same chip; and (3) touching the chips but not saying the counting words in the right sequence (e.g. 1, 2, 5, 7). In the most sophisticated counting problem (i.e. Item 5) just one child was able to count all the chips and give the right answer. The errors made by the sixteen children who were unsuccessful in counting were: (1) counting all the chips; (2) skipping some chips while counting; and (3) counting one or more chips twice. The common strategy used by children who successfully solved counting Items 1, 4, and 5, was touching the chips in a systematic fashion, proceeding from right to left.

In the items that required children to compare two stacks of chips that differ in height in a visually obvious way (i.e. Items 2 and 3), most of them (i.e. eleven children) were able to tell which pile had more chips. Fewer children, but still the majority (i.e. nine children), were able to say which stack had less chips. Children who failed these items seemed not to understand the words more/less and simply started to play with the chips.

The test recommended going to Level 1 if three or more answers in Level 0 are correct, only six children got three or more right answers in Level 0 , and thus they were administered the items of Level 1. Results show that none of the children were able to answer Item 1 whereas just one child was able to correctly answer Items 2, 3 and 4. None of them could answer the remaining items. 


\subsection{Kindergartners}

Although Level 1 corresponds to the age of the kindergarten children, Level 0 was also applied to them as to analyze the performance of children on this less advanced level. The performance of the kindergartners in Level 0 was as follows (see Table 1): twenty one out of thrity two children confidently counted from 1 to 10 (preliminary item of the test). The remaining eleven children failed in saying the string of the counting words in the correct order. The common mistake was to leave out one or more numbers in the sequence (e.g. 1, 2, 3, 5, 6, 8, 9, and 10).

The majority of the children (i.e. twenty seven children) succeeded in counting a set of three chips that were placed in front of them (Item 1). The remaining five children were unable to solve this item; the common mistake made by all of them was to say more words than chips touched. Fewer children, but still the majority (i.e. twenty children), were successful in solving Item 4 which required them to count a set of four yellow chips that are intermixed with three red chips in a row. Twelve children failed solving this problem. Unsuccessful children usually mismatched the number words with the correct number of chips. In the most complex problem of this level (i.e. Item 5) that required children to count a set of eight red chips that were intermixed with seven yellow chips in a randomly distributed array, thirteen children came up with the right answer, whereas nineteen of them did not; the most common errors were: (1) forgetting which chip they started with; (2) counting one or more chips twice; and (3) mismatching the number words with the correct number of chips. In all the problems that required children to count, the most common strategy used by children was touching the chips in a systematic fashion and saying the number word. They usually proceeded from right to left. Most of the children (i.e. thirty children) gave a right answer in the items that required them to tell which stack had more or less chips (Items 2 and 3).

Turning to Level 1 items, it was strikingly found that none of the children were capable of giving a correct answer to Item 1 that required adding 4 plus 3 chocolates. The strategy they used when trying to solve this item was to show the fingers while trying to count but they failed to give the correct answer. Most of them responded by saying "I don't know", by taking a wild guess (e.g. "nine"), or by simple not saying anything. Only eight children knew the answer to Item 2 (i.e. what number comes right after 7). Even fewer children (i.e. five children) responded correctly to Item 3 that required them to tell which number comes two numbers after 7 . For both items the strategy used by successful children was to count up from one. Those who failed responded by taking a wild guess or by saying "I don't know". When asked the question "how do you know?" (This question applies only to children who correctly answer Items 1, 3, and 7 at Level 1) their answers were very limited; they said "because I know"; "my mother told me"; or simply did not say anything.

A minimum number of children (i.e. two children) were able to tell which of two single-digit numbers was bigger or smaller (Items 4 and 5). The common error made by children who failed these items was to repeat the last number pronounced by the test-applier; for instance, for the question "which is bigger five or four", they answered "four". None of the children could answer the rest of the items.

\subsection{Teachers'interview}

In relation to the first question (i.e. teachers' background) it was found that none of the three teachers possessed a preschool/kindergarten teaching diploma. The preschool teacher had an Educational Psychology diploma whereas both kindergarten teachers had a Primary School diploma. In relation to the years of teaching experience (Question 2), it was found that the preschool teacher as well as one of the kindergarten teachers had been working with young children for 6 years while the other kindergarten teacher had been teaching for 23 years at this level.

On the question if the teachers felt prepared to teach mathematics to young children (Question 3), all of the teachers said that they did not know how to support children's knowledge of mathematics for the following reasons: (1) they did not learn how to do it during their training; (2) there were inconsistency of ideas in the workshops or seminars they attended addressed at improving young children's education; and (3) lack of adequate literature. When asked about their belief regarding young children's informal mathematical knowledge (Question 4), they said that most of their children grew up in disadvantaged environments most likely lacking mathematical experiences; hence, they 
concluded that children did not possess informal mathematical knowledge. For this reason, they believed that instruction in the preschool and kindergarten must be narrow and limited. Additionally, teachers considered that it would be very difficult for those children to learn important mathematics competencies (Question 5), such as counting, simple addition and subtraction, problem solving and others, since young children do not have the capacity to learn such skills. By contrast, when they were asked how important it was for the children to learn relevant mathematical concepts (Question 6) they all said that it was very important because it forms the basis for later mathematical learning.

In Question 7 the teachers were asked to name the mathematical competencies taught to their children. The preschool teacher said that she concentrates in teaching some notions (e.g. big-small; inside-outside and so on), basic colors and recognition of shapes (circle, square, triangle and rectangle). The kindergarten teachers said that to prepare children for school entry they focused on teaching notions (e.g. near-far; up-down; and so forth), colors, geometric shapes (circle, square, triangle and rectangle), classification, ordering, conservation, route counting (from 1 to 10), making collections up to 5 objects, and writing the numbers from 1 to 5 .

In relation to the teaching approaches (Question 8), the three teachers mentioned that they plan activities beforehand, according to the class schedule. Most of the activities include a distribution of worksheets for children to work on them. They also said that direct teaching was more commonly used than opportunistic teaching and whole-class teaching more frequently used than co-operative learning in small groups and classroom discussion. Furthermore, when asked if children were required to give the reasons of their answers, they said that just occasionally some children were told to explain their answers.

Finally, the teachers were asked the number of hours per week that they spend teaching mathematics (Question 9). The answer was between 4 and 5 hours, roughly. They argued that young children do not like mathematics, but prefer other activities. They also were concerned that young children would be frustrated if the preschool/kindergarten curriculum is too advanced.

\section{DISCUSSION}

The study revealed that most of the preschool children of the case study public school were unsuccessful in answering the majority of the items in the test. Although more than half of them were able to compare two groups of objects that differ in size and tell which has more or less objects, most of them failed answering the items that required counting. Moreover, less than half of the children did not even succeed the preliminary item of the test that required a verbal counting from 1 to 10 . These results are in sharp contrast with research findings claiming that preschool children are capable of apprehending small collection of objects without counting (Baroody, 2004; Clements \& Sarama, 2007; Sarama \& Clements, 2009); able to count verbally from 1 to 10 (Sarama \& Clements, 2009); and understand the rules that underlie counting, i.e. one-to-one correspondence (each item must be counted only once) and cardinality (the last counting word indicates the cardinal value of a collection) (Gelman \& Gallistel, 1978). Unfortunately, many of the preschoolers in the present study did not develop such competencies yet; as it was found that they counted two times the same chip, or that they counted correctly three chips, but were not able to give the last number said in the answer. In addition, when asked to count a row of chips they counted proceeding from right to left; however, at this age, most of the children usually count proceeding from left to right (Griffin, 2005).

Regarding kindergartners, this study demonstrated that although most of them were able to find out how many objects there were in a collection of 3 and 4 objects, they were unsuccessful in using counting to determine the number of objects in a collection of 8 objects when presented in a mixed array. This differs from previous findings that state that at the age of 5 years, children are able to count scattered groups of objects greater than 10 (Sarama \& Clements, 2009). It was also found that they were unable to solve the addition problems (even though it involved small numbers). Contrary to these results, research suggests that 5-year-olds can solve simple addition and subtraction word problems even without having real objects available to count (Kilpatrick et al., 2001). Researchers have also found that kindergarten children are able to tell which number comes next in the counting sequence, 
and to determine (in the absence of countable objects) which of two numbers is bigger or smaller (Griffin, 2005). Nevertheless, as seen in the results section, just very few kindergartners were able to solve these problems. Furthermore, children's answers to the question "how did you figure that out?" for Items 3, Level 1, demonstrate their lack of ability to reflect on their own reasoning and communicate it in words. Finally, although these children are at an age when children typically count objects proceeding from left to right (Griffin, 2005), most of them counted proceeding from right to left.

The study reveals further that there was a strong belief among teachers that young children are neither capable of carrying out natural mathematical reasoning, nor enjoy mathematics. Based on this assumption, mathematical instruction is limited in general. Although the teachers stated that mathematics is important for children, they did not translate this belief into practice. In addition, teachers considered that teaching some basic notions, such as geometric shapes, colors, logical operations (classification, ordering and conservation), rote counting, and numbers-writing, are the most important skills for children to learn before entering elementary school. However, they did not take into account important competencies such as subitizing, number composition and decomposition or equal partitioning (Baroody, 2004; Sarama \& Clements, 2009). Moreover, a conversation about the methods of teaching revealed that children usually spend prolonged periods sitting at tables to complete pencil and paper tasks (which would be inappropriate even for substantially older children); that there is little opportunity for conversation among children and children and teachers, and that rarely advantage is taken of opportunities during the day to teach math (e.g. in outdoor physical games, during lunch time, and so on). On the other hand, as stated only 4 or 5 hours per week (out of the 22.5 hours children spend in the school) are on average designated to mathematics. Consequently, it is clear that the mathematical activities of children and teachers in the sample school are at the low side. The preliminary findings suggest low mathematics performance of preschool and kindergarten children in the case study school in Cuenca. However, more studies involving different - public and private - schools and teachers are needed to generalize these findings.

\section{CONCLUSIONS}

The study was carried out with the objective of assessing the level of mathematical competencies of children attending a public Ecuadorian preschool and kindergarten, as well as their teachers' beliefs and practices. With respect to children's competencies, our cross-sectional descriptive study demonstrated that the majority of preschool and kindergarten children do not possess the mathematical competencies identified as important for later mathematics understanding. In this context, it is necessary that all young Ecuadorian children, and especially children from low socioeconomic backgrounds (who are more at risk of academic failure), have the opportunity and are stimulated to develop during early school years a solid basis in mathematics. To ensure this, the ways in which today mathematics in public preschools and kindergartens is taught need to reflect current thinking and contemporary research on early childhood mathematics education. Therefore, a redefinition of the Ecuadorian kindergarten mathematics curriculum that incorporates the development of the Big Ideas among other current trends in math education will be beneficial for advancing children's mathematics growth and development. This might stimulate children's early mathematical knowledge and skills and thus might prepare them academically for grade one and beyond. Conversely, the consequences of ignoring the early childhood mathematics education could be detrimental for the children as they could become victims of a spiral of failure and frustration.

On the other hand, it was found that teachers' beliefs and practices in the studied school influence inversely the way in which mathematics is approached. Their belief that young children do not enjoy using mathematics or that they are not capable of carrying out complex mathematical thought negatively affect the time dedication and the customization to the age level of mathematical instruction. Therefore, it is necessary that teachers change their attitudes towards children capacities and become aware that children possess a mathematical potential that should be developed with appropriate methods of instruction. Additionally, there is a need for more pre- and in-service training 
for Ecuadorian teachers so that they know how to support children's knowledge of mathematics. Having a more explicit understanding of the current state-of-the-art about young children mathematical competencies will help teachers to evolve their teaching from heavily mediated teaching, known as explicit instructing, to teaching with an increasing amount of active learning. The main task of teachers should be to stimulate the children, to incorporate them actively in the learning process, to bring the classroom to life (Griffin, 2004: 179).

In addition, it is important that all the people working in the field of education, i.e. government representatives, principals, teachers, school leaders, and others, contribute to improve the quality of early mathematics education that children receive. Among other measures, certainly a curriculum review must be conceived with great care, starting by studying recent research in the subject area.

A limitation of this study is the fact that findings reflect the situation of one single public school. Another limitation is that given the small sample of surveyed children and interviewed teachers, broad conclusions regarding the status of mathematics in preschool and kindergarten settings cannot be drawn. However, given the large fraction of young children at national level attending public preschools and kindergartens, the risk that many youngsters fall behind in mathematical development is not unlikely. To come up with the most appropriate and complete measures to improve mathematical instruction at preschool and kindergarten level in Ecuador's public schools further research in this area is more than necessary. Future studies should pursue a deeper analysis of children's strategies and mistakes, include class observations, encompass intervention studies where the effectiveness of existing intervention programs for children's math development is tested, and foresee the follow-up of groups of children over longer periods of time.

\section{REFERENCES}

Aunio, P., M. Niemivirta, 2010. Predicting children's mathematical performance in grade one by early numeracy. Learn. Individ. Differ., 20, 427-435.

Barnett, W.S., C.R. Belfield, 2006. Early childhood development and social mobility. Future Child., 16(2), 73-98.

Baroody, A.J., 2001. The developmental bases for early childhood number and operations standards. Invited paper written for the follow-up conference to the Conference on Standards for Preschool and Kindergarten Mathematics Education. Dallas, Texas, USA.

Baroody, A.J., 2004. The developmental bases for early childhood number and operations standards. In: Clements, D.H., J. Sarama, A.-M. DiBiase (Eds.), Engaging young children in mathematics: Standards for early childhood mathematics education, pp. 173-219. Publisher: Mahwah, NJ, Lawrence Erlbaum Associates Inc.

Baroody, A.J., M. Cibulsksis, M. Lai, X. Li, 2004. Comments on the use of learning trajectories in curriculum development and research. Math. Think. Learn., 6, 227-260.

Baroody, A.J., M.-I. Lai, K.S. Mix, 2006. The development of young children's number and operation sense and its implications for early childhood education. In: Spodek, B., O.N. Saracho (Eds.), Handbook of research on the education of young children (2 ${ }^{\text {nd }}$ ed.), pp. 187-221.

Bereiter, C., S. Engelman, 1966. Teaching disadvantaged children in the preschool, $312 \mathrm{pp}$. Englewood Cliffs, NJ: Prentice-Hall.

Clements, D.H., 2004. Major themes and recommendations. In: Clements, D.H., J. Sarama, A.-M. DiBiase (Eds.): Engaging young children in mathematics: Standards for early childhood mathematics education, pp. 7-72. Publisher: Mahwah, NJ, Lawrence Erlbaum Associates Inc.

Clements D.H., J. Sarama, 2007. Early childhood mathematics learning. In: Lester, F.K., Jr. (Ed.), Second handbook of research on mathematics teaching and learning. Charlotte, NC: Information Age, 724 pp.

Clements D.H., J. Sarama, C.B. Wolfe, 2011. Tools for early assessment in math (TEAM). Teacher's Guide. Mc Graw Hill Education Series. 
Copley, J.V., 2004. The early childhood collaborative: A professional development model to communicate and implement the standards. In: Clements, D.H., J. Sarama, A.-M. DiBiase (Eds.), Engaging young children in mathematics: Findings of the 2000 national conference on standards for preschool and kindergarten mathematics education, pp. 83-87. Publisher: Mahwah, NJ, Lawrence Erlbaum Associates Inc.

De Smedt, B., L. Verschaffel, P. Ghesquiere, 2009. The predictive value of numerical magnitude comparison for individual differences in mathematics achievement. J. Exp. Child Psychol., 103, 469-479.

Duncan, G.J., C.J. Dowsett, A. Claessens, K. Magnuson, A.C. Huston, P. Klebanov, C. Japel, 2007. School readiness and later achievement. Dev. Psychol., 43, 1428-1446.

Evans, G.W., J. Rosenbaum, 2008. Self-regulation and the income-achievement gap. Early Child. Res. Q., 23(4), 504-514.

Fuson, K., 2004. Pre-K to grade 2 goals and standards: Achieving 21st century mastery for all. In: Clements, D.H., J. Sarama, A.-M. DiBiase (Eds.), Engaging young children in mathematics: Standards for early childhood mathematics education, pp. 105-148. Mahwah, NJ: Lawrence Erlbaum Associates Inc.

Geary, D., 2011. Cognitive predictors of achievement growth in mathematics: A 5-year longitudinal study. Dev. Psychol., 47, 1539-1552.

Gelman, R., C.R. Gallistel, 1978. The child's understanding of number. Cambridge, MA: Harvard University Press.

Ginsburg H.P., A.J. Baroody, 2003. Test of early mathematics ability ( $3^{\text {rd }}$ ed.). Austin, TX: PRO-ED.

Greenes, C., H.P. Ginsburg, R. Balfanz, 2004. Big math for little kids. Early Child. Res. Q., 19, 159166.

Griffin, S., 2004. Building number sense with number worlds: A mathematics program for young children. Early Child. Res. Q., 19, 173-180.

Griffin, S., 2005. Fostering the development of whole-number sense: Teaching mathematics in the primary grades. In: Donovan, M.S., J.D. Bransford (Eds.) How Students Learn: History, mathematics, and science in the classroom. Committee on How People Learn, A Targeted Report for Teachers. Division of Behavioral and Social Sciences and Education, Washington DC: The National Academies Press.

Griffin, S., R. Case, 1997. Re-thinking the primary school math curriculum: An approach based on cognitive science. Issues Educ., 3, 1-49.

Jordan, N.C., J. Glutting, C. Ramineni, 2010. The importance of number sense to mathematics achievement in first and third grades. Learn. Individ. Differ., 20, 82-88.

Jordan N.C., D. Kaplan, L.N. Olah, M.N. Locuniak, 2006. Number sense growth in kindergarten: A longitudinal investigation of children at risk for mathematics difficulties. Child Dev., 77, 153175.

Jordan N.C., D. Kaplan, C. Ramineni, M.N. Locuniak, 2009. Early math matters: Kindergarten number competence and later mathematics outcomes. Dev. Psychol., 45, 850-867.

Kilpatrick, J., J. Swafford, B. Findell, 2001. Adding it up. Helping children learn mathematics. Washington DC, National Academy Press.

Krajewski, K., W. Schneider, 2009. Exploring the impact of phonological awareness, visual-spatial working memory, and preschool quantity-number competencies on mathematics achievement in elementary school: Findings from a 3-year longitudinal study. J. Exp. Child Psychol., 103, 516531.

Ministerio de Educación, 2012. Rendición de cuentas 2011, Quito, Ecuador.

Ministerio de Educación (2013). Archivo maestro de instituciones educativas AMIE. Reporte de registros educativos 2013-2014.

Piaget, J., 1969. The psychology of the child. New York: Basic Books. 
Raudenbush, S.W., 2009. The Brown legacy and the O'Connor challenge: Transforming schools in the images of children's potential. Educ. Res., 38, 169-181.

Sarama, J., D.H. Clements, 2009. Early childhood mathematics education research: Learning trajectories for young children. New York: Routledge.

Sophian, C., 2004. Mathematics for the future: Developing a head start curriculum to support mathematics learning. Early Child. Res. Q., 19, 59-81.

Starkey, P., A. Klein, A. Wakeley, 2004. Enhancing young children's mathematical knowledge through a pre-kindergarten mathematics intervention. Early Child. Res. Q., 19, 99-120.

UNESCO, 2008. El Laboratorio Latinoamericano de Evaluación de la Calidad de la Educación (LLECE). Los aprendizajes de los estudiantes de América Latina y el Caribe, Santiago, Chile.

Van de Rijt, B.A.M., J.E.H. Van Luit, A.H. Pennings, 1999. The construction of the Utrecht early mathematical competence scales. Educ. Psychol. Meas., 59, 289-309.

Warfield, J., 2001.Teaching kindergarten children to solve word problems. ECEJ, 28, 161-167.

Wright, R.J., 1994. A study of the numerical development of 5-year-olds and 6-year-olds. Educ. Stud. Mathem., 26, 25-44. 


\section{Appendix 1}

Number Knowledge Test (Griffin, 2005)

\section{Preliminary Item}

Let's see if you can count from 1 to 10 . Go ahead.

\section{Level 0 (4-year-old level): Go to Level 1 if 3 or more correct.}

1. Can you count these chips and tell me how many there are? (Place 3 counting chips in front of child in a row.)

2. a. (Show stacks of chips, 5 vs. 2 , same color.) Which pile has more?

b. (Show stacks of chips, 3 vs. 7, same color.) Which pile has more?

3. a. This time I'm going to ask you which pile has less. (Show stacks of chips, 2 vs. 6 , same color.) Which pile has less?

b. (Show stacks of chips, 8 vs. 3, same color.) Which pile has less?

4. I'm going to show you some counting chips (Show a line of 3 red and 4 yellow chips in a row, as follows: R Y R Y R Y Y). Count just the yellow chips and tell me how many there are.

5. (Pick up all chips from the previous question.) Here are some more counting chips (show mixed array [not in a row] of 7 yellow and 8 red chips.) Count just the red chips and tell me how many there are.

\section{Level 1 (6-year-old level): Go to Level 2 if 5 or more correct.}

1. If you had 4 chocolates and someone gave you 3 more, how many chocolates would you have altogether?

2. What number comes right after 7 ?

3. What number comes two numbers after 7 ?

4. a. Which is bigger: 5 or 4 ?

b. Which is bigger: 7 or 9 ?

5. a. This time, I'm going to ask you about smaller numbers. Which is smaller: 8 or 6 ?

b. Which is smaller: 5 or 7 ?

6. a. Which number is closer to 5:6 or 2? (Show visual array after asking the question.)

b. Which number is closer to 7:4 or 9? (Show visual array after asking the question.)

7. How much is $2+4$ ? (OK to use fingers for counting.)

8. How much is 8 take away 6 ? (OK to use fingers for counting.)

9. a. (Show visual array 8526 . Ask child to point to and name each numeral.) When you are counting, which of these numbers do you say first?

b. When you are counting, which of these numbers do you say last?

\section{Level 2 (8-year-old level): Go to Level 3 if 5 or more correct.}

1. What number comes 5 numbers after 49 ?

2. What number comes 4 numbers before 60 ?

3. a. Which is bigger: 69 or 71 ?

b. Which is bigger: 32 or 28 ?

4. a. This time I'm going to ask you about smaller numbers. Which is smaller: 27 or 32 ?

b. Which is smaller: 51 or 39 ?

5. a. Which number is closer to 21:25 or 18 ? (Show visual array after asking the question.) 
b. Which number is closer to $28: 31$ or 24 ? (Show visual array after asking the question.)

6. How many numbers are there in between 2 and 6? (Accept either 3 or 4 .)

7. How many numbers are there in between 7 and 9? (Accept either 1 or 2.)

8. (Show visual array 1254 .) How much is $12+54$ ?

9. (Show visual array 4721 .) How much is 47 take away 21 ?

\section{Appendix 2}

\section{Teachers' questionnaire}

1. Do you have a teaching diploma? If yes, what is your diploma title?

2. How long have you been working as a preschool/kindergarten teacher?

3. Do you feel trained to teach mathematics in the early grades?

4. Do you think that children develop informal mathematics knowledge of before entering preschool/kindergarten?

5. Do you think that preschool/kindergarten children are capable of learning number and arithmetic skills (e.g., counting, simple addition and subtraction)?

6. Do you consider important to teach mathematics to preschoolers/kindergartners? Why?

7. Could you list the mathematical competencies that you teach in this school level?

8. What are the teaching strategies used to teach mathematics in your class?

9. How many hours per week do you devote to the teaching of mathematics? 